\title{
Examination of the Level of State- Trial Anxiety of Elite Level Archers from Several Variables
}

\author{
Haluk Saçakli \\ Correspondence: Haluk Saçakli, Istanbul Gelişim University, Turkey. \\ Received: February 11, 2019 \\ Accepted: February 20, 2019 Online Published: March 11, 2019 \\ doi:10.11114/jets.v7i4.4046 \\ URL: https://doi.org/10.11114/jets.v7i4.4046
}

\begin{abstract}
The purpose of this study is to examine the state and trait anxiety levels of the individuals who perform archery sports at the elite level according to different variables. The population of the study was held from constitute archers who participated in the archery tournament "Turkey Cup" in 2018 ( $\mathrm{N}=421)$. Also, the sample of the research was the volunteer athletes determined by the simple random sampling method $(\mathrm{n}=156)$. The study was conducted by applying the causal comparison method in the screening model. The data collected by the survey technique. Participants were provided with a personal information form and Trait and State Anxiety Inventory. The obtained data transferred to SPSS 22 packet program and one-way ANOVA and Independent Sample T-test statistic applied as the statistical process for study purpose. This study demonstrates that there was a significant difference between the participants' level of trait anxiety according to gender variable and state anxiety levels according to the bow categories they used. Also the study demonstrates that there was a significant difference between the participants' level of trait anxiety according to gender variable and state anxiety levels according to the bow categories they used.
\end{abstract}

Keywords: archery, anxiety, elite athletes, sports psychology

\section{Introduction}

Today, many factors affecting the level of sportive efficiency are mentioned. Some of these factors are evaluated under the name of environmental factors, while others are under the name of internal factors. One of the internal factors of the athletes is the psychological factors. The psychological preparations of the athletes are an essential factor for success. The psychological status of the athletes and the performance they will exhibit are closely related to their level of anxiety (Gülşen, 2008). Complex reactions such as anxiety, fear, stress, involuntarily emerging are challenging to deal with. The athletes who can control these situations can purely exhibit their performances. Thus, the chance of success is higher because they are not exposed to a psychological effect.

Researches show that contests are the situations that cause anxiety for athletes. The positive or negative impact of this situation on success depends on many factors such as the person's personality, age, gender, living conditions, experience, and environmental conditions (Samur \& Samur, 2018). The approach of the coaches is so important for the athletes' motivation. Unfortunately, today's coaches are not fully aware of how the athlete's reactions and performance will be affected if anxiety and its reactions in their derivative are more than optimal. Moreover, these coaches are entirely success-oriented. For example; a successful archer cannot concentrate on a target in a lot of complex thoughts, such as worrying that after waiting for a series of low scores in a race, afraid of failing, people expect success from him, especially his coach's success. These cause other shots to get worse. In such a case, the coaches should remove these worries from the athletes' minds. The coach has two ways in such a situation. Either by motivation and by reducing the athlete's concerns, he will either win the athlete, or approach him negatively, and be both successful and lacking the confidence of his athlete.

This study conducted to determine the anxiety levels of athletes concerning various variables. It is thought that there is a relationship between the state and trait anxiety levels and the quality of sportive performance of elite athletes according to the different variables. This study is also essential for the correct approach to the athletes' anxiety levels. There are very few studies in the literature about archery. When officially examined, no study has been found on the level of anxiety of archers. It is considered that this study will shed light on the scientists and the trainers for both archery sports which are rarely studied scientifically. 


\section{Method}

\subsection{Subjects}

For the purpose of the study, the population of the study was composed of constitute archers who participated in the archery tournament "Turkey Cup" $(\mathrm{N}=421)$. Also, the sample of the researcher is the volunteer athletes determined by simple random sampling method $(n=156)$. Participants were provided with a personal information form (gender, age, bow preference, sports experience) and Trait and State Anxiety Inventory.

\subsection{Trait and State Anxiety Inventory}

Trait and State Anxiety Inventory developed by Spielberger et al. adapted to Turkish by Öner and Le Compte (Spielberger, 1983; Öner \& Le Compte, 1983). In the State Anxiety Inventory, 10 items (1,2,5,8,10,11,15,16, 19, and 20) were encoded in reverse, while 7 items $(1,6,7,10)$ in the Trait Anxiety Inventory were encoded in reverse. Alpha reliability of the scale was between 83 and 87 , test-retest reliability ranged between. 71 and. 86 , and the reliability of the item ranged from. 34 to. 72. The total scores of the 4-point Likert type direct and inversed sentence's overall scores calculated. The total score for the direct expression subtracted from the total score of the reversed expressions. An unchanging value added to this number. This value is 50 in the State Anxiety Inventory and 38 in the State Anxiety Inventory. The most recent value is the person's anxiety score (Öner N \& Le Compte, 1998).

\subsection{Analysis of the Data}

The data collected by the survey technique. The study was conducted by applying the causal comparison method in the screening model. The scale consists of 20 parts "state anxiety form" formed to identify the feelings and 20th item "trait anxiety form" which is formed to determine generally feelings. Data from the personal information form, Trait and State Anxiety Inventory were entered into the SPSS22.0 package program and analyzed made through this program. Personal information about the candidates, inventory averages and factor scores supplied by determining the frequency (f) and percent $(\%)$ values. Parametric and nonparametric distribution of points; parametric and nonparametric distribution curves surveyed by examining the skewness-kurtosis values. The data showed a parametric distribution. One-way ANOVA and Independent Sample T-Test analysis used as the statistical procedures.

\section{Results}

\subsection{Statistics and Data Analysis}

Table 1. Participants' Socio-Demographic Characteristics

\begin{tabular}{lccc}
\hline Characteristic & Variables & $\mathbf{N}$ & $\mathbf{f}$ \\
\hline \multirow{2}{*}{ Gender } & Women & 42 & 26,9 \\
& Men & 114 & 73,1 \\
Age & Total & 156 & 100,0 \\
& $14-24$ aged & 87 & 55,8 \\
& $25-35$ aged & 17 & 10,9 \\
& $36-46$ aged & 32 & 20,5 \\
Bow Preference & 47 and over & 20 & 12,8 \\
& Total & 156 & 100,0 \\
Sport Experience & Compound & 46 & 29,5 \\
& Recurve & 110 & 70,5 \\
& Total & 156 & 100,0 \\
National Athlete Status & $1-3$ years & 77 & 49,4 \\
& $4-6$ years & 39 & 25,0 \\
& 7and above & 40 & 25,6 \\
& Total & 156 & 100,0
\end{tabular}

When we examined Table 1, it is determined that among the participants; $26.9 \%$ were female, $73.1 \%$ were male, $55.8 \%$ were between the ages $14-24,10.9 \%$ of them were between the ages $25-35,20.5 \%$ of them were between the ages $36-46$ and, $12.8 \%$ of them were above 47 years old; $29,5 \%$ of them were using compound bow, $70,5 \%$ of them were using recurve bow, $49.4 \%$ of them had between 1-3 years of sports experience, $25 \%$ of them had between 4-6 years of sports experience, $25.6 \%$ of them had 7 years and above. In addition, $\% 10,9$ of the participants were in national team, $\% 89.1$ were not in national team. 
Table 2. Descriptive Statistics of the Participants' Answers to the Scale

\begin{tabular}{lllll}
\hline Type of anxiety & $\mathbf{N}$ & Min & Max & X \pm Ss \\
\hline State Anxiety & 156 & 1,25 & 3,90 & $60,63 \pm 9,78$ \\
Trait Anxiety & 156 & 1,00 & 3,50 & $40,94 \pm 9,00$ \\
\hline
\end{tabular}

This study revealed that the mean of the responses of the participants to the state anxiety level scale was $60,63 \pm 9,78$ and, the average of the answers to the trait anxiety scale was 40,94 $\pm 9,00$. The state anxiety level averaged $61.35 \pm 9.42$, $60.26 \pm 10.12$ for $4-6$ years, $59.63 \pm 10.26$ for 7 years and over were determined to be between 1-3 years of sports experience. The average level of trait anxiety among those with 1-3 years of sports experience was 40,81 $\pm 9,30$, and those with 4-6 years were found to be 42,00 \pm 9,23 and those with 7 years and above were 40,18 $\pm 8,30$ (Table 2).

Table 3. Assessment of State Anxiety and Trait Anxiety Levels of Participants According to Their Genders

\begin{tabular}{|c|c|c|c|c|c|}
\hline Type of anxiety & Gender & $\mathbf{N}$ & $\mathrm{X} \pm \mathrm{Sd}$ & $\mathbf{t}$ & p \\
\hline \multirow{2}{*}{ State Anxiety } & Women & 42 & $60,00 \pm 10,09$ & \multirow{2}{*}{,- 491} & \multirow{2}{*}{,624 } \\
\hline & Men & 114 & $60,87 \pm 9,70$ & & \\
\hline \multirow{2}{*}{ Trait Anxiety } & Women & 42 & $42,21 \pm 8,32$ & \multirow{2}{*}{1,071} & \multirow{2}{*}{,028 } \\
\hline & Men & 114 & $39,47 \pm 9,23$ & & \\
\hline
\end{tabular}

Table 3 indicates that there was no significant difference observed between the participants regarding the state anxiety levels of participants according to gender, conversely, there was a significant difference between participants' trait anxiety levels according to gender, $\mathrm{p}=, 028$.

Table 4. Evaluation of State Anxiety and Trait Anxiety Levels by Participants' Age

\begin{tabular}{|c|c|c|c|c|c|c|c|}
\hline Type of anxiety & Type of group & $\begin{array}{ll}\text { Sum } & \text { of } \\
\text { Squares } & \\
\end{array}$ & sd & $\begin{array}{l}\text { Quadratic } \\
\text { Mean }\end{array}$ & $\mathbf{F}$ & $\mathbf{p}$ & Difference \\
\hline \multirow{4}{*}{ State Anxiety } & Intergroup & 169,161 & 3 & 56,387 & \multirow{4}{*}{, 585} & \multirow{4}{*}{,626 } & \multirow{4}{*}{-} \\
\hline & Within-Group & 14657,012 & 152 & 96,428 & & & \\
\hline & Total & 14826,173 & 155 & & & & \\
\hline & Intergroup & 124,544 & 3 & 41,515 & & & \\
\hline \multirow{2}{*}{ Trait Anxiety } & Within-Group & 12441,936 & 152 & 81,855 & \multirow{2}{*}{, 507} & \multirow{2}{*}{,678 } & \multirow[b]{2}{*}{-} \\
\hline & Total & 12566,481 & 155 & & & & \\
\hline
\end{tabular}

When Table 4 is examined, it is determined that there was no significant difference between the state anxiety levels of the participants according to their age, $F(3,152)=585, p<0,010$. Similarly, there was no significant difference between the trait anxiety levels of the participants according to their age, $F(3,152)=507, p<0,010$.

Table 5. Evaluation of State Anxiety and Trait Anxiety Levels by Participants' Bow Preference

\begin{tabular}{|c|c|c|c|c|c|}
\hline Type of anxiety & Bow Preference & $\mathbf{N}$ & $\mathbf{X} \pm$ Sd & $\mathbf{t}$ & p \\
\hline \multirow{2}{*}{ State Anxiety } & Compound & 46 & $57,63 \pm 11,31$ & & \\
\hline & Recurve & 110 & $61,05 \pm 9,09$ &,- 828 & - 2009 \\
\hline Trait Anxiety & $\begin{array}{l}\text { Compound } \\
\text { Recurve }\end{array}$ & $\begin{array}{l}46 \\
110\end{array}$ & $\begin{array}{l}40,28 \pm 9,44 \\
4122+8,85\end{array}$ &,- 591 &, 556 \\
\hline
\end{tabular}

As it can be seen in Table 5, there appeared to be a meaningful difference between the levels of state anxiety according to the bow categories used by the participants $(p=, 009)$. However, there was no significant difference between partic ipants' trait anxiety levels.

Table 6. Evaluation of State Anxiety and Trait Anxiety Levels According to the Sports Experience

\begin{tabular}{lccccccc}
\hline Type of anxiety & type of group & $\begin{array}{l}\text { Sum of } \\
\text { Squares }\end{array}$ & sd & $\begin{array}{l}\text { Quadratic } \\
\text { Mean }\end{array}$ & F & p & Difference \\
\hline \multirow{5}{*}{ State Anxiety } & Intergroup & 85,830 & 2 & 42,915 & & & \\
& Within-Group & 14740,343 & 153 & 96,342 &, 445 &, 641 & - \\
Trait Anxiety & Total & 14826,173 & 155 & & & & \\
& Intergroup & 68,628 & 2 & 34,314 & & & \\
& Within-Group & 12497,853 & 153 & 81,685 &, 420 &, 658 & - \\
\hline
\end{tabular}

When Table 6 is examined There was no significant difference between the levels of state anxiety according to participants' sports experience, $\mathrm{F}(2)=445, \mathrm{p}>0,050$, and, there was no significant difference between the levels of trait anxiety according to participants' sports experience, $F(2)=420, p>0,050$.

Table 7. Evaluation of State Anxiety and Trait Anxiety Levels According to Being a National Athletes

\begin{tabular}{|c|c|c|c|c|c|}
\hline & National Team & $\mathbf{N}$ & $\mathrm{X} \pm \mathrm{Sd}$ & $\mathbf{t}$ & $\mathbf{p}$ \\
\hline State Anxiety & $\begin{array}{l}\text { Yes } \\
\text { No }\end{array}$ & $\begin{array}{l}17 \\
139\end{array}$ & $\begin{array}{l}61,82 \pm 8,49 \\
60,49 \pm 9,94\end{array}$ &, 530 &, 597 \\
\hline Trait Anxiety & $\begin{array}{l}\text { Yes } \\
\text { No }\end{array}$ & $\begin{array}{l}17 \\
139\end{array}$ & $\begin{array}{l}40,76 \pm 10,38 \\
40,96 \pm 8,86\end{array}$ &,- 086 & ,932 \\
\hline
\end{tabular}


Table 7 indicates that there was no significant difference between state anxiety levels according to the being a national athlete status, and also there was no significant difference between the level of trait anxiety according to being a national athlete status of participants.

\section{Discussion}

In our study, there was no significant difference between the state anxiety levels of the participants according to gender, and we also found that there was a considerable difference between the trait anxiety levels of the participants according to gender. Basaran et al. found that male athletes had higher state anxiety scores than female athletes. Considering these results, a large number of studies needed in order to determine whether the anxiety differs according to gender (Basaran, 2009). Engür indicated in the study "The Effect of Success Motivation on Elite Anxiety Levels in Elite Athletes" which has 55 women, $224 \mathrm{men}$, and total 279 athletes in the study as a result of the research, when compared with the state anxiety levels according to gender, no statistically significant difference was found (Engür, 2002). Öğüt showed no difference between the trait anxiety total score and gender (Öğ̈̈t, 2000).

When we examined the state anxiety levels of the participants according to their age, no statistically difference was found. Also, Civan and his friends reported in their study "The comparison of state and trait anxiety levels of individual and team athletes before and after the competition" it was found that there was no statistical significance in terms of both trait anxiety score and state anxiety score according to the age groups (Civan, 2010). These results can interpret as the age variable does not make any difference between the anxiety levels of the athletes.

There was a significant difference between the state anxiety levels of the participants according to the bow categories they used. There is no significant difference between the trait anxiety levels of the participants according to their bow categories. When the results were evaluated, it is thought that the springs used in archery sports have different ergonomic characteristics and they affect the performance of the athlete in some ways. As a result of the literature review, similar studies with archery athletes have not been observed.

In our study, no statistically significant difference was found between the state and trait anxiety levels according to the sports experience of the participants. Nacar and his friends reported in their study "Trait Anxiety Levels of the Handball Players regarding Some Variables" that the trait anxiety scores of the participants did not differ according to the years of sports experience and they had similar values (Nacar et al., 2011).

According to Karabulut et. al. In the study of state and trait anxiety levels of 13-15 years old boys concerning different variables, there was no significant difference between the sports experiences variable and the state anxiety scores (Karabulut, Atasoy, Kaya, Karabulut, 2019). Arseven and Güven, Yücel, Erbaş, Adalı, Bingöl et al. in their works with different groups, found that athletes did not affect the trait and state anxiety levels. (Arseven \& Güven, 1992, Yücel, 2003, Erbaş, 2005, Adal1, 2006, Bingöl et. al., 2012). The findings support our findings of the research. These results can interpret as the sports experiences variable does not cause any difference between the anxiety levels of the athletes. While our research is supported by the studies of Özbekçi 's the state anxiety levels, Engür's the effect of success motivation on state anxiety and Yücel 's the state and trait anxiety levels of taekwondo, it contradicted with the results of other studies.

Our study has found that there is no significant difference between the state anxiety levels of the participants according to their being a national athlete status and, also there is no significant difference between the trait anxiety levels according to the being a national athlete status of the participants. When the results are evaluated, it is thought that there is no difference between the anxiety levels of the athletes according to their being a national athlete status and the fact that there is not enough number of national and non-athletes.

In our study, there was no significant difference in trait and state anxiety scores of the participants. It was determined that there be a substantial difference between the state anxiety levels and the trait anxiety levels of the participants according to the gender variable. According to Kremer and Scully, trait anxiety was a constant personality characteristic. Due to the fact that trait anxiety was accepted as a personality trait, it would be wrong to expect changes in trait anxiety level in a short period. Continuous anxiety was considered a personality dimension that reflects the non-temporary and the manner or attitude of the individual in a certain way (Kremer \& Scully, 1994). Civan and his friends found no significant difference between the state and trait anxiety scores of the athletes according to the variables (Civan, 2010).

As the result, archery sports is one of the sports branches that require an optimum level of attention and concentration. It is thought that the level of anxiety in athletes may adversely affect sportive performance regarding some variables. Trainers should choose athletes for archery and should keep their anxiety levels to a minimum. Psychologists should teach athletes how to cope with anxiety. The social environment that the athlete comes from must search well, and his / her concern should be approached gradually. Considering that the success and failure of the athletes after the competition, affects the trait anxiety scores, they should develop a trait anxiety inventory which includes defeats and disabilities, and the most appropriate equipment should be selected for the physical structure of the athlete. 


\section{References}

Adalı, F. (2006). Comparison between the socio-demographic aspect of 14-18-year-old basketball players both girl and, and the level of the assertiveness and trait anxiety, MA thesis, Institute of Educational Sciences, Gazi University, Ankara.

Arseven, A, \& Güven, Ö. (1992). Anxiety levels of athletes in the competitive environment]. Hacettepe Üniversitesi, Spor Bilimleri II. Ulusal Kongresi, Ankara.

Başaran, M. H., Taşğın, Ö., Sanioğlu, A., \& Taşkın, A. K. (2009). Examination of The Level of State - Trial Anxiety of Sportsmen According to Some Variables. S.Ü.Sosyal Bilimler Enstitüsü Dergisi; 21(1) 533-542.

Bingöl, H., Çoban, B., Bingöl, Ş., \& Gündoğdu, C. (2012) Determine the Anxiety Level of National Team Taekwondo Athletes before Matches Who Studied at Universities. Selçuk Üniversitesi, Beden Eğitimi ve Spor Bilimleri Dergisi, 14(1), 121-125.

Civan, A., Ar1, R., Görücü, A., \& Özdemir, M. (2010). Comparison of the pre and post-game state and trait anxiety levels of individual and team athletes. International Human Science Journal, 7(1), 193-206.

Engür, M. (2002). The effect of achievement motivation on state anxiety levels of elite athletes, MA thesis, Institute of Health Sciences, Ege University, İzmir.

Erbaş, M. K. (2005). The Anxiety level of the upper-level basketball players and relate them with performance]. MA thesis, Institute of Social Sciences, Dumlupınar University, Kütahya.

Gülşen, D. (2008). Analyzing, the players who are playing in different division levels and the problem-solving abilities of the soccer players according to the league, education levels, and sports age, MA thesis. Institute of Health Sciences, Çukurova University, Adana.

Karabulut, E. O., Atasoy, M., Kaya, K., \& Karabulut, A. (2019). The Examination of the State-Trait Anxiety Levels of the Male Football Players at the Age of 13-15 in Terms of Different Variables. Ahi Evran Üniversitesi Kırşehir Eğitim Fakültesi Dergisi, 14(1), 243-253.

Kremer, J. D., \& Scully, D. M. (1994). Psychology in Sport. London: Taylor \& Francis Ltd

Nacar, E., Imamoğlu, O., Karahüseyinoğlu, M. F., \& Açak, M. Research on Levels of Trait Anxiity in Handball Players in Terms of Certain Variables. E-Journal of New World Sciences Academy, 6(1), 2-12.

Öğüt, F. (2000). The Relation between social adjustment and trait anxiety, MA thesis, Institute of Health Sciences, Kocaeli University, Kocaeli.

Öner, N., \& Le Compte, A. (1998). Manual of Unsteady State/Trait Anxiety Inventory. İstanbul: Boğaziçi University Publications.

Öner, N., \& Le Comte, A. (1983). Handbook of state-trait anxiety inventory. Istanbul: Bogazici University Publications.

Özbekçi, F. (1989). Investigation of the stress levels experienced in different sports competitions, MA thesis. Institute of Social Sciences, Marmara University, İstanbul.

Samur, S., \& Samur, Ü. G. (2018). Stress Management and Techniques in Sport. Ankara: Gazi Publications.

Spielberger, C. D. (1983). Manual for the State-Trait Anxiety Inventory STAI (Form Y). Palo Alto, CA: Consulting Psychologists Press.

Yücel, O. (2003). Effects of Taekwondo athletes on state and trait anxiety levels and their success in competitions, MA thesis, Institute of Health Sciences, Gazi University, Ankara.

\section{Copyrights}

Copyright for this article is retained by the author(s), with first publication rights granted to the journal.

This is an open-access article distributed under the terms and conditions of the Creative Commons Attribution license which permits unrestricted use, distribution, and reproduction in any medium, provided the original work is properly cited. 